\title{
XXIV. On the magnetizing power of the more refrangible solar rays
}

\section{Mrs. M. Somerville}

To cite this article: Mrs. M. Somerville (1826) XXIV. On the magnetizing power of the more refrangible solar rays, Philosophical Magazine Series 1, 68:341, 168-173, DOI: $10.1080 / 14786442608674105$

To link to this article: http://dx.doi.org/10.1080/14786442608674105

册 Published online: 10 Aug 2009.

Submit your article to this journal $₫$

Џll Article views: 2

Q View related articles $₫$ 
outside, could measure both columns before it had time to change its temperature; but the other is surely sufficiently accurate.

Experiments of this kind, I intended to have made during the cold weather, but did not get them attended to, and the season is now too far advanced for conveniently obtaining the requisite temperatures.

The expansions of the columns or the difference in their lengths, may be increased or rendered more sensible by lengthening the tubes. But care must be taken to keep each bath at the same temperature throughout its whole depth. By placing a pretty wide tube open at both ends upright in the bath, and moving a solid piston in it, the temperature may be easily rendered uniform from top to bottom. Indeed, the motion of a piston alone, without a tube, would probably be sufficient.

The method proposed by Mr. Oswald Sym*, though quoted with approbation by Dr. Thomsont, is entirely a deception. It can at best give the temperature answering to the apparent greatest density of water in glass; just as if the water were in a bottle, and its height measured in the neck.

April 15, 1826.

Henry Meikle.

XXIV. On the magnetizing Porwer of the more refrangible Solar Rays. By Mrs. M. Somerville $\neq$.

I $\mathrm{N}$ the year 1813, Professor Morichini, of Rome, discovered that steel exposed to the violet rays of the solar spectrum becomes magnetic. His experiments were repeated by Professor Configliachi, at Pavia, and also by Mons. Berard, at Montpellier, without success. I am not aware of any one having attempted them in this country, perhaps from the belief that experiments which had sometimes failed in Italy, were not likely to succeed in our more northern climate. The unusual clearness of the weather last summer, however, induced me to try what could be accomplished in this country. Accordingly, in the month of $\mathrm{July}$, an equiangular prism of flint glass, the three sides of which were each $1 \cdot 4$ by $1 \cdot 1$ inch, was fixed in a slit made to receive it in a window-shutter: by this prism a coloured spectrum was thrown on an opposite panel, at the distance of about five feet. I used for the subject of experiment a very slender sewing-needle an inch

* Annals of Philosophy, vol. ix. page 387.

+ System of Chemistry, 6th edition, vol. i. page 43.

\# From the Philosophical Trinsactions for 1826 , Part I. This paper was communicated to the Royal Society, Feb. 2, 1826. 
long, having previously ascertained that it was quite free from magnetism, by repeated exposure of both ends of it to the north and south pole of a very sensible magnetic needle, when it was found equally to attract either pole in every instance. The magnetic needle employed as a test in this experiment, is made of a sewing-needle magnetized, and run through a small piece of cork, into which a conical cap of glass is inserted; the whole traverses on the point of a needle fixed perpendicularly in a stand.

$I$ had no information at this time of the manner in which Professor Morichini had conducted his experiments; but it occurred to me that it was not likely if the whole of the needle were equally exposed to the violet rays, the same influence should, at the same time, produce a south pole at one end of it, and a north pole at the other. I therefore covered half of the needle with paper, and fixed it to the panel with wax, between ten and eleven in the morning, in such a position that the uncovered part of it should be exposed to the violet rays. The needle was placed in a vertical plane, nearly perpendicular to the magnetic meridian, and inclined to the horizon. As 1 had not a heliostat, it was necessary to move the needle in a direction parallel to itself, to keep the exposed portion of it constantly in the violet ray.

The sun was bright at the time, and in less than two hours I had the gratification to find that the end of the needle which had been exposed to the violet rays attracted the south pole of the magnetic needle, and repelled the north pole. It had been previously ascertained that there was no iron near to disturb the results. 'Ihe experiment was also repeated on the same day, under precisely similar circumstances, with the view of detecting any source of error that might have escaped observation in a first attempt; but the result was the same as in the first.

The season was so favourable that it afforded me daily opportunity of repeating the experiments, varying the size of the needles, always taking especial care to ascertain that they were free from magnetism. The needles were placed in various directions in the plane of the magtetic meridian, sometimes in the angle of the dip, sometimes perpendicular to the magnetic meridian, and also at various angles with regard to it. In some cases the heads of the needles were exposed in place of the points, to the violet rays. Perhaps it might have been expected that the influence would have been greater in those instances in which the needles were placed in the plane of the magnetic meridian, and at the angle of the dip; and, consequently, polarity might have been expected to take place in a Vol. 68. No. 341. Sept. 1826. 
shorter time under these circumstances; yet in fact, there seemed to be no difference; most of the needles became magnetic, some in longer, others in shorter periods, varying from about half an hour to four hours, but depending on circumstances which I have not yet been able to detect, further than that a number of results induced me to believe, that the experiments were more successful from ten to twelve, or one o'clock, than later in the day. The portion of the needle exposed was almost always a north pole, whether it pointed upwards or downwards : in a few instances in which the contrary occurred, it may possibly have arisen from some previous disposition in the needle to magnetism, too slight to be observed.

The distance of the needle from the prism was frequently varied by fixing the needle to the wooden pole of a fire-screen, but without material variation in the effect. I found it unnecessary to darken the room; it was sufficient to place the prism so as to throw the spectrum on any place out of the sun's rays.

My next object was to endeavour to ascertain whether any other of the more refrangible rays had the same property as the violet. A set of needles carefully examined as before, were therefore subjected to the different rays of the solar spectrum: the needles exposed to blue and green rays, sometimes acquired the magnetic property, though less frequently, and requiring longer exposure than when the violet rays were used; but the magnetism seemed to be equally strong in these as in the examples of the violet rays. The part exposed became a north pole. The indigo rays succeeded almost as well as the violet.

Pieces of cluck and watch-spring were next tried, under the idea that they might, possibly from their blue colour, be more susceptible of magnetic influence,-and it was the case; their greater extent of surface, however, or their softness, may have contributed to this susceptibility. The pieces of spring were from two to three inches long, and from the eighth to the half of an inch broad. It was difficult to procure watch and clockspring fiee from magnetism; it even happened an one occasion, that although the roll of spring was neutral, the pieces into which it was cut became magnetic; in one instance the pieces were heated so as to deprive them of magnetism and colour; they then required longer exposure to the rays, in order to acquire polarity. Large bodkins were exposed to the violet rays without effect, the mass perhaps being too great. When needles already magnetic were tried, their magnetism was increased. Dr. Wollaston was so kind as to lend me a very large lens, having its centre covered with paper, which he had used in his investigations respecting the chemical rays. 
The lens concentrated the violet rays, and produced a magnetic effect in a shorter time than the prism; but the rapid motion of the sun made it difficult to keep the needle in the focus. The effect was produced with equal facility by throwing the spectrum on the floor of the room; but success could not always be depended upon even when the weather seemed most favourable.

I now made the following experiments with blue glass:Three needles free from magnetism, having one half covered with paper, were laid horizontally on the stone outside of a south window, under a dark blue glass coloured by cobalt, in a very hot sun; after remaining in this position between three and four hours, they were found to have become feebly magnetic; the uncovered part being a north pole. On examining these needles the following day, they had lost their magnetism, a circumstance which had not before occurred, though it was observed sometimes to take place afterwards, as the force of the sun diminished from the advance of the season. There was no iron near, and the magnetic needle when placed on various parts of the stone, showed no magnetic influence in it. Next day the experiment was repeated with this difference, that the needles were left exposed to the sun, under the blue glass, six hours; and then the needles had not only acquired very sensible magnetism, but still retain it, at the distance of nearly six months. Pieces of clock-spring, which had been heated as formerly mentioned, also became magnetic under the blue glass.

I was desirous of ascertaining whether this kind of glass suffered the chemical rays to pass, and thereby occasion these changes in the steel, therefore I employed a liquid holding muriate of silver in suspension, as a test, in the following manner: A piece of writing paper dipped in the liquid was cut into two equal parts, of which one was placed under the blue glass, and the other under a white glass, as nearly at the same time as possible; but the one did not become black sooner than the other; nor on comparing them could any difference be perceived in intensity of colour, both having been equally exposed to the chemical rays. The experiment was repeated with the same result.

On the 26th of August, the thermometer at noon being $66^{\circ}$, two neutral pieces of clock-spring were exposed to the sun, one under a thicker piece of the same blue glass, as in the former experiment, and the other under green glass; both acquired polarity.

31 st of August, the thermometer at noon $68^{\circ}$. Having thus Y 2 succeeded 
succeeded in producing magnetism under the circumstances described; I next tried the effect of exposing neutral pieces of clock-spring to the sun, enveloped in violet and green silk. The half of each was covered with paper as before, and the pieces of spring then wrapped, one in green, and the other in violet-coloured ribbon, were fixed to the inside of a pane of glass in a window, where they were left exposed to the sun all day; in the evening both had become magnetic, although they were two of the pieces of spring already said to have acquired polarity more slowly, from having been heated; and as before, the parts exposed to the sun under the ribbon were north poles.

To learn if heat had any share in producing magnetism in this case, I exposed three pieces of the same steel to a bright sunshine, on the 1st of September, the thermometer at noon being at $70^{\circ}$ : one half of each was covered with paper, but the other half had neither glass nor ribbon over it; and although the heat was greater than on the preceding day, no magnetism was produced.

On the $2 \mathrm{~d}$ of September, thermometer at noon $68^{\circ}$; a piece of, neutral white steel acquired polarity from exposure to the sun, enveloped in green ribbon, one half being covered with paper as before.

On the 3rd of September, thermometer at noon $68^{\circ}$; two pieces of neutral spring became magnetic, one exposed in a violet-caloured ribbon, and the other in blue glass; while a similar piece of spring was in no way affected by exposure to white light: the half of each was covered with paper.

September the 4 th, thermometer at noon $68^{\circ}$; five large sewing-needles, two inches long, were exposed to the sun's rays, one in blue glass, one in green glass, one in violet ribbon, one in green ribbon, and one in white light; the half of each was covered with paper. Of all these, two only became magnetic; namely, those in the blue glass, and in the violet ribbon.

On the 20 th of September, thermometer at $69^{\circ} ;$ I placed pieces of steel enveloped in violet and green ribbon, and under glass of various colours, in different positions with regard to the magnetic meridian and dip. Several acquired polarity, the uncovered part being the north pole. A piece of steel became more strongly magnetic than usual, exposed in green ribbon, the position of which had been perpendicular to the horizon, and nearly in the magnetic meridian. For some time I still obtained similar results, though the magnetism became more feeble as the season advanced, from the diminished force of the sun; in consequence of which further experiments were 


\section{Mr. Howldy on the Electric Inflammation of Gunporeder. 173}

deferred till the return of summer shall afford me an opportunity of continuing them.

From the results which have been stated, I am induced to believe that the more refrangible rays of the solar spectrum have a magnetic influence even in this country.

XXV. On the Inflammation of Gunporoder by Electricity. By $M r$. Thomas Howldy.

To the Editor of the Philosophical Magazine and Journal. Sir,

THROUGH the medium of your very useful Magazine and Journal, your ingenious correspondent Mr. Sturgeon has communicated to the public, some observations and experiments concerning the ignition of gunpowder by the charge of a Leyden jar. But as Mr. Sturgeon's method of performing the experiment is not so certain in its effect, nor more simple than Cavallo's, and as a better than Cavallo's* does not seem to have been yet made public, you will, perhaps, sir, favour me by communicating to the cultivators of electrical science, a method which I contrived more than twelve years ago, of inflaming with ease and certainty, either loose or confined gunpowder by electricity; especially as it saves the experimenter time, labour, and power.

By describing the manner in which the original experiment was conducted, the method will immediately be understood, and may be readily practised by any electrician. A jar, containing about 160 square inches of (interior) coated surface, was placed at the prime conductor, and the points of the wires of the universal discharger were set upon the table of that instrument, at the distance of one inch and a quarter from each other. A chain, which was laid upon the bare surface of the table supporting the machine and apparatus, had one of its extremities placed at the' distance of four inches from the bottom or outside of the jar; while its other extremity was annexed to the negative end of the universal discharger. By this arrangement, two interruptions were made in the electrical circuit; the first or that between the points of the

* See his Elements of Natural or Experimental Philosophy, vol. iii. page 411. It may be here stated, likewise, that both Mr. Tatum and Mr. Lewthwaite, in their lectures on electricity delivered at the London $\mathrm{Me}$ chanics' Institution, had recourse to Cavallo's " water tube," as it is called by the reporter of the lectures, in order to effect the experiment in question. See the London Mechanics' Register, vol. i. p. 84, and vol. ii. p. 36 . 